\title{
Morphology of the sacral region and reproductive strategies of Metriorhynchidae: a counter-inductive approach
}

\author{
Yanina Herrera ${ }^{1,2,5,6^{*}}$ Marta S. Fernández ${ }^{1,6}$, Susana G. Lamas ${ }^{3}$, \\ Lisandro Campos $^{1}$, Marianella Talevi ${ }^{4,6}$ and Zulma Gasparini ${ }^{5,6}$
}

${ }^{1}$ División Paleontología Vertebrados, Unidades de Investigación Anexo Museo, Facultad de Ciencias Naturales y Museo, Universidad Nacional de La Plata, Av. 60 y 122, B1900AVW La Plata, Argentina.

${ }^{2}$ Bayerische Staatssammlung für Paläontologie und Geologie, Richard-Wagner-Straße 10, 80333 Munich, Germany. Email: yaninah@fcnym.unlp.edu.ar

${ }^{3}$ Cátedra de Lógica y Metodología de la Ciencia, Facultad de Ciencias Naturales y Museo, Universidad Nacional de La Plata, Av. 60 y 122, B1900AVW La Plata, Argentina.

${ }^{4}$ Instituto de Investigación en Paleobiología y Geología, Universidad Nacional de Río Negro, Isidro Lobo y Belgrano, R8332EXZ General Roca, Río Negro, Argentina.

${ }^{5}$ División Paleontología Vertebrados, Museo de La Plata, Facultad de Ciencias Naturales y Museo, Universidad Nacional de La Plata, Paseo del Bosque s/n, W1900FWA La Plata, Argentina.

${ }^{6}$ CONICET

* Corresponding author

\begin{abstract}
Morphological and physiological features indicate Metriorhynchidae as the only group of crocodylomorphs with a pelagic lifestyle. Some of these features have evolved convergently in several clades of tetrapods secondarily adapted to aquatic life. One striking feature of metriorhynchids as compared to other crocodylomorphs is the morphology of the pelvic region (i.e., ventrally deflected sacral ribs and reduced pelvic girdle), which increases significantly the depth of this region. This morphology, as a whole, resembles that of other viviparous Mesozoic marine reptiles not phylogenetically related to metriorhynchids. We tested two alternative hypotheses of reproductive strategies in this clade: oviparity vs. viviparity. Given the lack of direct evidence supporting one or the other, we explored the use of evidence that may disconfirm either of these hypotheses. Using this counter-inductive approach, we found no cases contradicting viviparity in metriorhynchids, except for their phylogenetic position as archosaurs. A survey of reproductive modes amongst amniotes depicts the evolutionary plasticity of the transition to viviparity, and a widespread occurrence among tetrapods secondarily adapted to a marine life. Assuming oviparity for metriorhynchids implies egg-laying out of the water. However, their postcranial morphology (i.e., features of fore and hind limbs, pelvic girdle, and tail) contradicts this possibility. In this context, we rejected oviparity for metriorhynchids.
\end{abstract}

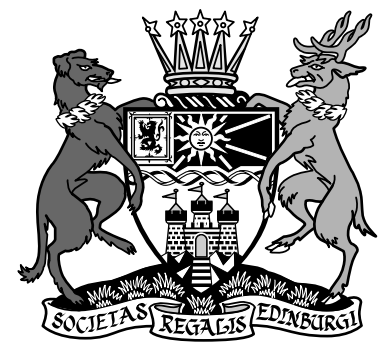

KEY WORDS: Crocodylomorpha, Jurassic, metriorhynchids, Neuquén Basin, Thalattosuchia, viviparity.

The fossil record depicts crocodylomorphs as a morphologically disparate and ecologically diverse clade. Within this clade, morphological and physiological features indicate that Metriorhynchidae was the only group with a pelagic lifestyle. Some morphological features that distinguish metriorhynchids from other crocodylomorphs have evolved convergently in several clades of tetrapods secondarily adapted to aquatic life, such as hydrofoil limbs, a hypocercal tail, an 'osteoporotic-like' histology and orbits facing laterally (e.g., Fraas 1902; Andrews 1913; Hua \&Buffrénil 1996; Young et al. 2010). Coupled with these features, the exquisite preservation of natural endocasts of the skull cavities of metriorhynchids has shown the presence of enlarged and highly vascularised nasal glands and a reduced olfactory tract and bulb, indicating the achievement of osmoregulation via salt glands and an under-developed aerial olfaction (Fernández \& Gasparini 2000, 2008; Herrera et al. 2013a). Both biological capabilities are also present in other marine reptiles in the first case, and in aquatic reptiles in the second.

Another striking feature of metriorhynchids amongst crocodylomorphs is the strong ventral deflection of the sacral ribs. This feature, together with the rearrangement of the pelvic bones, significantly increases the depth of the pelvic region (Young et al. 2010), giving a peculiar pattern to the pelvic region as a whole. Notably, the increased cross-section area of the pelvic region resembles that of other viviparous Mesozoic marine reptiles not phylogenetically related to metriorhynchids, such as basal sauropterygians, ichthyosaurs, mosasaurs and plesiosaurs (in which viviparity has been confirmed based on fossilised gravid females). In the case of metriorhynchids, there is no direct evidence of their parity mode, that is, no gravid female or egg-containing embryos have been found to support either oviparity or viviparity.

In the present paper, additional lines of evidence are used to test two alternative hypotheses in metriorhynchids: egg-laying (oviparity); and bearing live young (including egg retention and viviparity). Traditional and recent reviews of the reproductive strategies in reptiles (including Mesozoic marine forms) avoid dealing with the second hypothesis and assume oviparity to be the only reproductive strategy in archosauromorphs (Organ et al. 2009). The oviparity hypothesis in metriorhynchids is mainly supported by their phylogenetic position within archosaurs, and based on comparisons with living 


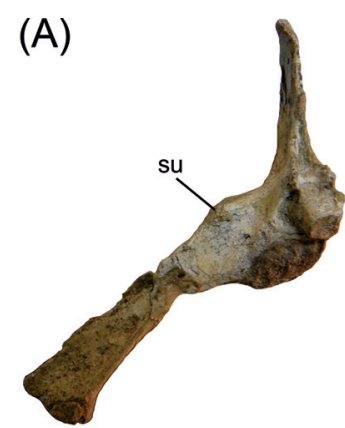

(C)

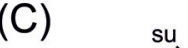

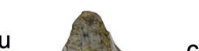

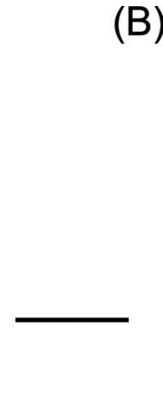

(D)
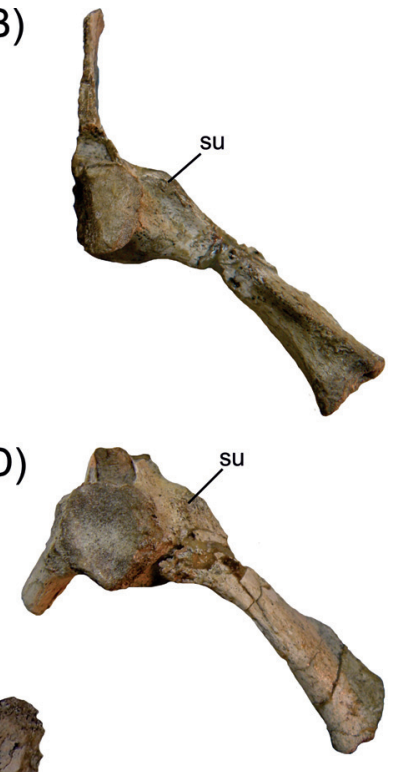

(E)

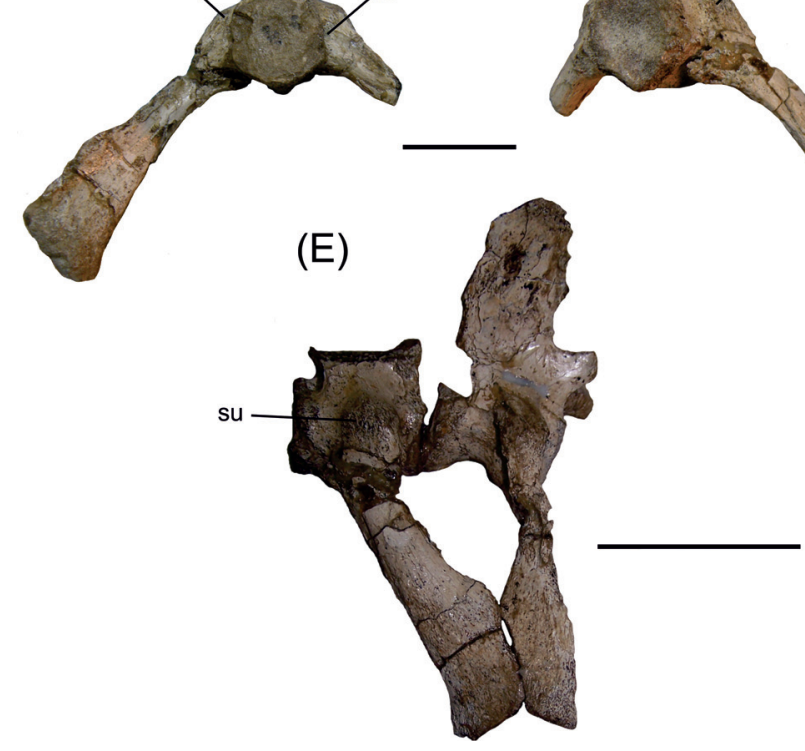

Figure 1 Cricosaurus araucanensis, MLP 72-IV-7-1, sacral ribs: (A) first sacral vertebra in anterior view; (B) first sacral vertebra in posterior view; (C) second sacral vertebra in anterior view; (D) second sacral vertebra in posterior view; (E) articulated sacral vertebrae in right lateral view. Scale bars $=3 \mathrm{~cm}(\mathrm{~A}-\mathrm{D}) ; 5 \mathrm{~cm}(\mathrm{E})$. Abbreviations: $\mathrm{co}=$ concavity; $\mathrm{su}=$ suture.

archosaurs (birds and crocodiles). As all living archosaurs are oviparous and some extinct archosaurs (i.e., dinosaurs and pterosaurs) were oviparous, it is generalised that all archosaurs (extinct and extant) were oviparous. However, certain aspects of metriorhynchids have been overlooked, such as the morphology of the pelvic region and hind limb. According to a counter-inductive approach, these aspects should be analysed, as they contradict the possibility of locomotion on land, and therefore also contradict oviparity as a putative reproductive strategy in this clade. Viviparity in metriorhynchids has been suggested since the 1970s by some authors (e.g., Neill 1971; Gasparini 1978, 1981), based on postcranial features such as the absence of osteoderms, the reduced and paddle-like forelimbs and the long hypocercal tail.

The main objective of this present study is to analyse the pelvic region morphology of Cricosaurus araucanensis (Gasparini \& Dellapé 1976), in order to test if the peculiar morphology of the metriorhynchid pelvic region could be functionally linked to a live-bearing reproductive strategy. The authors studied the morphology of the pelvic region of $C$. araucanensis and available information on reproductive patterns of extant reptiles. They use these two information sources to test the two alternative reproductive strategies (oviparity vs. viviparity) for metriorhynchids.

Institutional abbreviations. GPIT, Institut für Geowissenschaften Biogeologie, Tübingen, Germany; MLP, Museo de La Plata, Buenos Aires, Argentina; MOZ, Museo Juan Augusto Olsacher de Zapala, Neuquén, Argentina; NHM, Natural History Museum, London, UK; SMNS, Staatliches Museum für Naturkunde, Stuttgart, Germany.

\section{Material and methods}

Amongst the metriorhynchids, we selected Cricosaurus araucanensis for morphological exploration of the pelvic girdle. Reconstruction of the pelvic area was based on two specimens (the holotype MLP 72-IV-7-1 and MLP 73-II-27-6) in which the pelvic bones are preserved three-dimensionally. Sacral vertebrae, both ilia and ischia, and the right femur of MLP 72-IV-7-1, were completely removed from the matrix. Based on the similar body size of MLP 72-IV-7-1 and MLP 73-II$27-6$, the elements not preserved in the former were reconstructed using the complementary preserved elements (i.e., the ischiadic wing and the pubis) of MLP 73-II-27-6.

Three-dimensional models of the pelvic region of MLP 72-IV-7-1 and of an extant caiman were created using a NextEngine 3D scanner HD Desktop. Image data manipulation was carried out using ScanStudio HD software. The .ply files were then entered into MeshLab software v1.3.3 and the left sacral ribs, which are not preserved in specimen MLP 72-IV-7-1, were digitally reconstructed (using a duplicated and inverted layer created from the original layer) and the overlapped regions were deleted. Posteriorly, the contacts of the preserved elements of the pelvic girdle were made digitally. Finally, the ischiadic wing and the pubis were drawn, based on the scaled and reconstructed elements.

The transverse thin section of Cricosaurus araucanensis (MLP 73-II-27-6) from the proximal third of femur diaphysis at the level of the fourth trochanter was selected in order to explore long bone microstructure. 

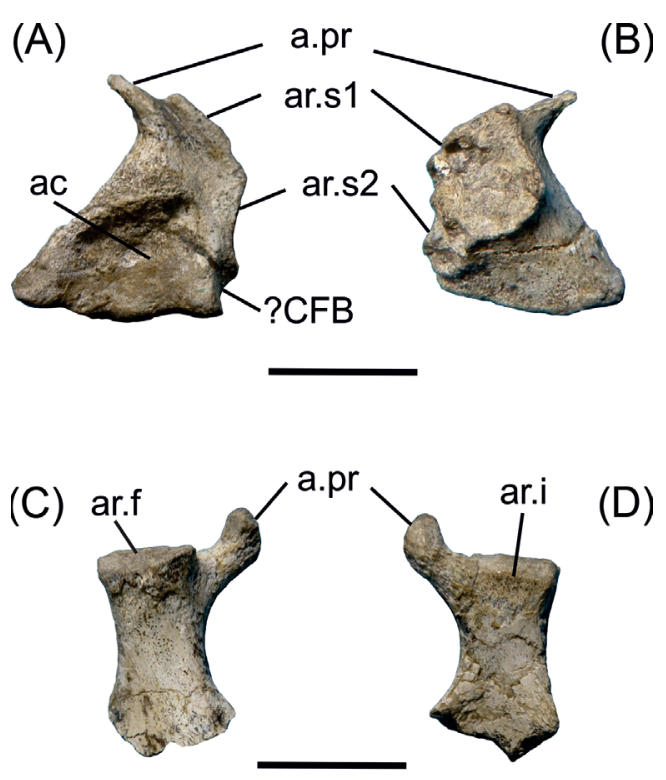

(D)

(E)
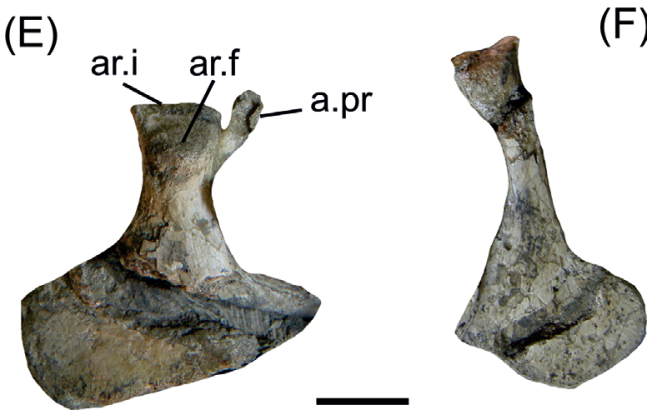

Figure 2 Cricosaurus araucanensis, pelvic girdle elements. (A-D) MLP 72-IV-7-1: (A) left ilium in lateral view; (B) left ilium in medial view; (C) right ischium in lateral view; (D) right ischium in medial view. (E-F) MLP 73-II-27-6: (E) right ischium in lateral view; (F) right pubis. Scale bars $=3 \mathrm{~cm}$. Abbreviations: ac = acetabulum; a.pr. $=$ anterior process; ar.f $=$ articular surface for the femur; ar.i. = articular surface for the ilium; ar.s = articular surface for sacral ribs; ?CFB $=M$. caudofemoralis brevis.

There is no direct evidence (i.e., eggs containing embryos or pregnant females) of the reproductive strategy of metriorhynchids. In this kind of situation, where the lack of direct evidence that supports one or the other hypothesis is 'problematic', two different approaches can be used: (1) an inductive approach, i.e., find cases that confirm the hypothesis; or (2) a counter-inductive approach, i.e., find cases that disconfirm the hypothesis. The authors chose the second approach and, based on morphological features of metriorhynchids and the published information on reproductive modes of extant forms, looked for cases that disconfirm two alternative hypotheses: metriorhynchids were oviparous (hypothesis 1); metriorhynchids were viviparous (hypothesis 2). The term 'viviparous' is used as referring to all forms that give birth to live young independently of the embryonic nutrition patterns (Blackburn 1994, 1999, 2015).

\section{Results}

\subsection{Sacral vertebrae and ribs}

In Cricosaurus araucanensis (MLP 72-IV-7-1 and MLP 73-II27-6), as in all metriorhynchids with the sacral region preserved (e.g., Cricosaurus suevicus, SMNS 9808; Metriorhynchus superciliosus, SMNS 10116, Andrews 1913; Dakosaurus maximus, Fraas 1902; Torvoneustes carpenteri, Wilkinson et al. 2008), the sacral ribs are ventrally deflected in such a way that the distal end is far below the ventral surface of the centra (Fig. 1).

In anterior and posterior views, the sacral ribs of Cricosaurus araucanensis form an angle of approximately $45^{\circ}$ with the sagittal axis of the vertebra (Fig. 1A-D). The suture between the transverse processes and the ribs can be observed in both vertebrae (Fig. 1). In the region where this suture takes place, the direction of the transverse process/sacral rib changes radically, from a lateral direction to a ventral direction. The distance between the ventral margin of the second sacral centrum and the distal margin of the second sacral rib is about 1.5 times the centrum length (Fig. 1C-D). In MLP 72-IV-7-1, the right transverse process of the first sacral vertebra is longer and more ventrally deflected than the second. In the anterior region of the second sacral vertebra, at about half the height of the centrum and near the transverse process/rib sacral suture, there is a small rounded concavity (Fig. 1C). The sacral rib of the first sacral vertebra is directed slightly backwards, while the sacral rib of the second vertebra is directed forwards (Fig. $1 \mathrm{E})$. In anterior view, the distal end of the first sacral rib is mediolaterally expanded (Fig. 1A), whereas in posterior view it is narrower (Fig. 1B). An opposite situation occurs in the second sacral vertebra (Fig. 1C-D). In lateral view, the distal end of the first sacral vertebra is less expanded anteroposteriorly than the second one (Fig. 1E).

\subsection{Ilium}

In MLP 72-IV-7-1, the left ilium is completely preserved (Fig. $2 \mathrm{~A}-\mathrm{B})$, whereas the right lacks the anterior process. It is subtriangular in shape, with a small and pointed preacetabular process. The postacetabular process is extremely reduced, therefore the acetabulum is very close to the posterodorsal margin of the ilium (Fig. 2A). The area between the posterodorsal margin of the acetabulum and the dorsal margin of the ilium is quite concave, and over the dorsal margin of the ilium there is an area with inconspicuous scars. Another feature that contrasts with extant (and many extinct) crocodiles is that the posterodorsal margin of the ilium is obliquely directed (from anterodorsal to posteroventral), rather than horizontally and anteroposteriorly oriented (Fig. 2A). The ventral margin is undulated, with the anterior and posterior side thicker mediolaterally than the medial region. The most anterior wave of the ventral margin of the ilium is where the anterior process of the ischium fits. The acetabulum is a shallow depression in comparison with extant crocodiles, and the supracetabular crest is particularly reduced (Fig. 2A).

The medial view of the ilium bears the insertion facets for the two sacral ribs. These facets form a bilobate area, with the anterior lobule larger and more dorsally orientated than the posterior one. All this area is very rough. The facet for the first sacral rib is slightly concave, whereas the facet for the second rib is more irregular with small ridges and concavities, indicating the presence of cartilage between the ilium and the sacral ribs (Fig. 2B).

It is difficult to discern distinct regions that suggest muscular attachments. The pointed preacetabular process would correspond to the insertion area for $M$. iliocostalis (muscle related to the lateral flexion of the trunk). The postacetabular process of the ilium, which is the origin of numerous muscular attachments in extant crocodiles, is much reduced in Cricosaurus araucanensis and other metriorhynchids (e.g., Metriorhynchus superciliosus, SMNS 10116; Tyrannoneustes lythrodectikos, Young et al. 2013). In the posterior margin of the ilium of MLP 72-IV-7-1, posterior to the acetabulum, there is a small and quite rounded fossa that would correspond to the attachment for M. caudofemoralis brevis (Fig. 2A). 

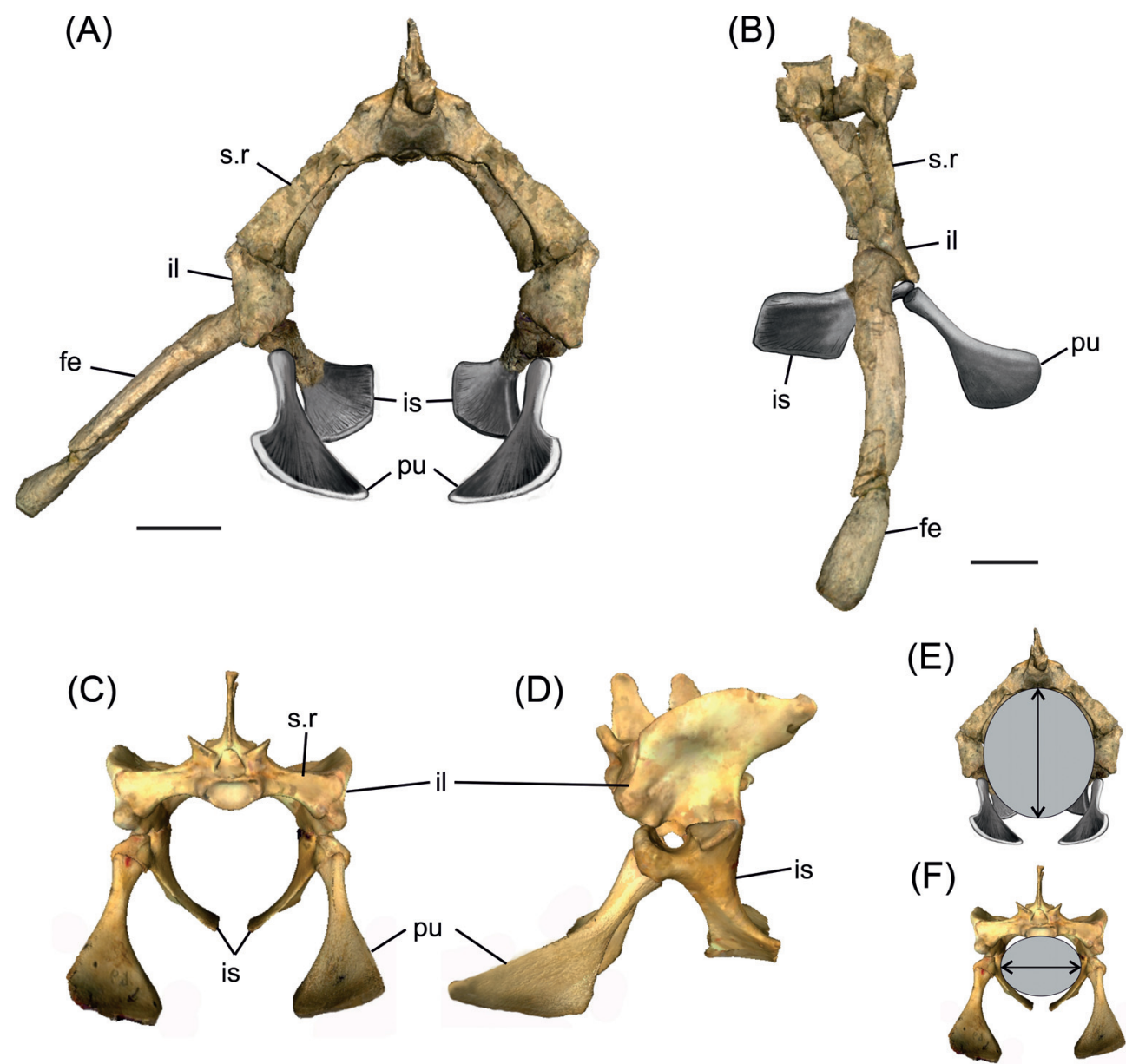

Figure 3 Reconstructed pelvic girdles. (A, B, E) Cricosaurus araucanensis: (A) anterior view; (B) lateral view; (E) cross-section of pelvic region showing direction of major axis. (C, D, F) Caiman: (C) anterior view; (D) lateral view; (F) cross-section of pelvic region showing the direction of major axis. Scale bars $=3 \mathrm{~cm}$. Abbreviations: $\mathrm{fe}=$ femur; il = ilium; is = ischium; $\mathrm{pu}=$ pubis; $\mathrm{s} . \mathrm{r}=$ sacral rib.

\subsection{Ischium}

The ischiadic wing is not preserved in either ischia of MLP 72IV-7-1 (Fig. 2C-D). The proximal region bears two processes: the anterior process is small and nearly circular in cross-section, and the posterior one large and subquadrangular in crosssection. The posterior process has two articular surfaces positioned in two planes. The articular surface for the femur is oblique to the major axis of the ischium (Fig. 2C), and the articular surface for the ilium is transverse to this major axis (Fig. 2E). In MLP 73-II-27-6, the right ischium is completely preserved and exposed in lateral view. The ischiadic wing is flat, with two clearly defined margins that form an angle of approximately $90^{\circ}$ with each other. The anterior margin is more than twice as long as the posterior, and is the surface for the union with the right ischium (Fig. 2E).

\subsection{Pubis}

In specimen MLP 73-II-27-6, the pubis is preserved and included in the matrix. These elements are not preserved in the holotype (MLP 72-IV-7-1). The pubis shaft is rod-shaped and the distal end is expanded. At the distal end, there is a straight area that may represent the pubic symphysis.

\subsection{Reconstructed pelvic girdle}

Based on the peculiar arrangement of the sacral ribs of Cricosaurus araucanensis, the ilium is ventrally displaced in relation to the vertebral column. The acetabulum is positioned much below the level of the vertebral column (Fig. 3A-B), a configuration of the pelvic region that strongly contrasts with the configuration present in extant crocodiles (Fig. 3C-D). As proposed by Claessens \& Vickaryous (2012), the present authors placed the pubis in contact with the anterior process of the ischium, without contact with the ilium, with the longest axis oriented transversely (Fig. 3A-D).

The ventrally deflected sacral ribs maximise the space between the vertebral column dorsally and the pubis and ischium ventrally (Fig. 3A). This arrangement results in an elliptical cross-section at the level of the pelvic region, with its major axis dorsoventrally oriented (Fig. 3E); by contrast, in extant crocodiles, the major axis is mediolaterally orientated (Fig. 3F). Measures of the elliptical cross-section of MLP 72-IV-7-1 were taken from the three-dimensional reconstruction; the dorsoventral axis is about $120 \mathrm{~mm}$ and the medio-lateral $100 \mathrm{~mm}$.

\subsection{Femur histology}

The microanatomy of MLP 73-II-27-6 is characterised by a lightening of the bone, as was reported in Metriorhynchus by Hua \& Buffrénil (1996), contrasting with the general pattern observed in the bone microstructure of extant crocodilians (Lee 2004). There is a compact periosteal cortex that surrounds a free medullary cavity (Fig. 4A). However, there is histological variation in different portions of the section. Zone A (Fig. 4B) is characterised by the well-vascularised cortical region, with parallel-fibred bone. The vascular canals are oriented longitudinally; the deep cortex is predominantly composed of compacted coarse cancellous bone and presents someone secondary osteons and few resorption cavities. Zone B (Fig. 4C) displays compacted coarse cancellous bone tissue, 


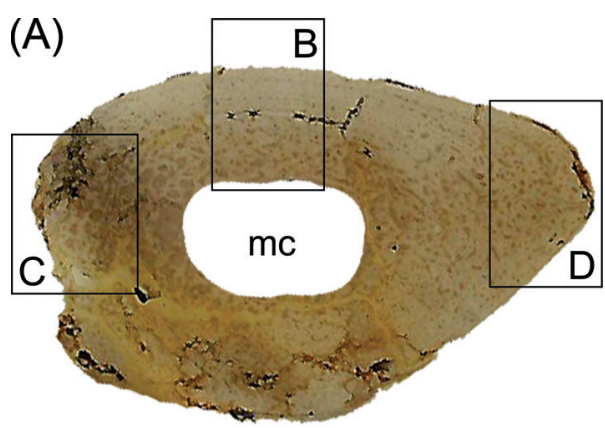

(B)

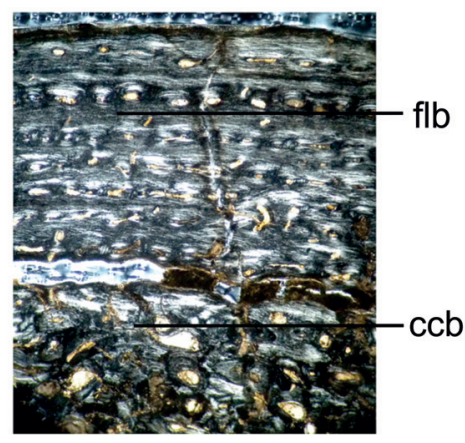

(C)

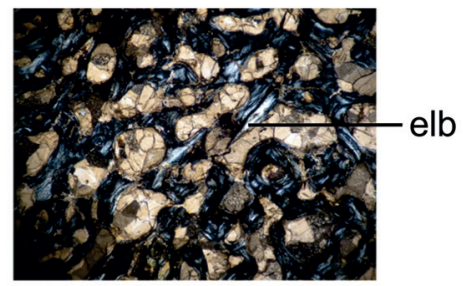

(D)

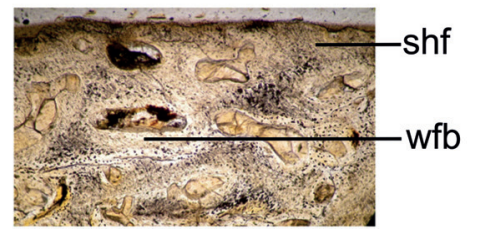

Figure 4 Cricosaurus araucanensis, MLP 73-II-27-6, microanatomy and histology of the femur: (A) general aspect of the proximal end femoral cross-section; (B) viewed under polarised light showing an fibro-lamellar bone and coarse compacted bone tissue; (C) cancellous bone formed with endosteal lamellar bone; (D) woven-fibered bone of the matrix and abundant Sharpey's fibres. Abbreviations: ccb = coarse compacted bone tissue; elb = endosteal lamellar bone; flb = fibro-lamellar bone; $\mathrm{mc}=$ medullary cavity; shf = Sharpey's fibres; $\mathrm{wfb}=$ woven-fibered bone. with a large resorption cavity and trabeculae of cancellous bone visible in the deep cortex. The presence of compacted coarse cancellous bone indicates that this tissue was produced during endosteal growth and was once located nearer the ends of the younger bone, and is the result of metaphyseal and diaphyseal remodelling (Chinsamy-Turan 2005). This type of tissue is common in regions that correspond to epiphysis initially, and subsequently formed part of the shaft. The microstructure in zone C (Fig. 4D) corresponds to the area of the fourth trochanter, and shows abundant woven-fibred bone and Sharpey's fibres, indicating the place or origin of M. caudofemoralis longus. The pattern observed in the femur agrees with the basic histogenetic mechanism from which lightening occurs in other marine tetrapods such as whales, ichthyosaurs, adult plesiosaurs and metriorhynchids (Hua \& Buffrénil 1996; Buffrénil et al. 2008). There is an imbalance between the resorption and subsequent reconstruction of bone; eroded bone is not entirely replaced by secondary (reconstructive) endosteal deposits (Buffrénil et al. 2008).

\section{Discussion}

\subsection{Comparative morphology of the pelvic region}

3.1.1. Non-metriorhynchid thalattosuchians (Crocodylomorpha). The pattern of the pelvic region of metriorhynchids, characterised by a high abdominal cross-section, is unique amongst crocodylomorphs, even as compared to other thalattosuchians. Thus, in Steneosaurus (GPIT/RE 07283, SMNS 9428, SMNS 17484a; Mueller-Töwe 2006), the sacral ribs are quite horizontally directed, with the distal end strongly expanded anteroposteriorly and dorsoventrally. The ilium of Steneosaurus is more quadrangular than in metriorhynchids. In Machimosaurus hugii, the sacral ribs bend ventrally toward their distal tip, which reaches the ventral level of the centrum (Martin \& Vincent 2013). In Pelagosaurus typus, although the sacral ribs curve ventrally, hanging below the level of the centrum (Pierce \& Benton 2006), the deflection of sacral ribs is much less than in Cricosaurus araucanensis. The second rib of P. typus is thicker than the first, and is more expanded at its lateral end, as was described for $C$. araucanensis. In P. typus, the ilium is squareshaped, with a shallow acetabular depression on its lateral surface (Pierce \& Benton 2006).

3.1.2. Mesozoic marine reptiles. A common feature in some Mesozoic marine reptiles (in which viviparity is supported

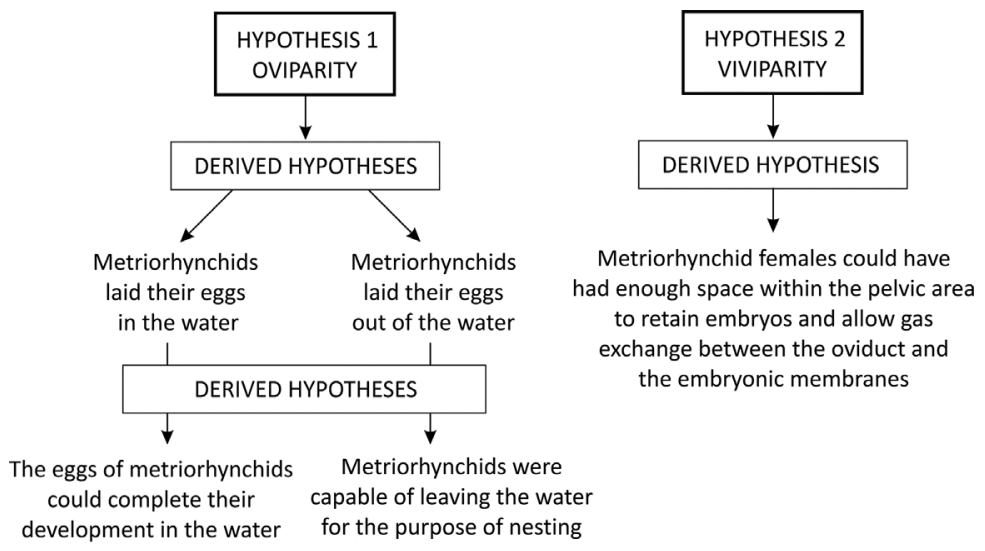

Figure 5 Schematic diagrams of the hypotheses on reproductive strategies of metriorhynchids tested. 
based on direct evidence) is an increase in abdominal depth at the level of the pelvic region. This large abdominal space can be achieved through two alternative patterns: (1) an elongated, columnar and ventrally directed ilium, so that the space between the vertebral column and ischium/pubis increases (e.g., ichthyosaurs, mosasaurs and plesiosaurs); or (2) elongated (longer than the centrum of the sacral vertebrae) and strongly ventrally deflected sacral ribs connected to the ilium (e.g., basal ichthyopterygians (Chaohusaurus, Utatsusaurus) and basal sauropterygians (Keichousaurus hui)). Clearly, each lineage has variations but, generally, these two patterns can be recognised. For example, more advanced forms, such as parvipelvian ichthyosaurs, do not have well defined sacral vertebrae, as the pelvic girdle loses contact with the column; in Keichousaurus hui, there is no solid connection between the pelvic girdle and the sacrum and the sacral ribs are never fused with the sacral vertebrae.

The morphology of the sacral region of Cricosaurus araucanensis resembles pattern 2. However, in metriorhynchids, the sacral ribs are fused to the sacral vertebra. Cheng et al. (2004) suggested that viviparity in Keichousaurus could have been expedited by its moveable pelvis, and extended this implication to all Mesozoic marine reptiles that possess a moveable pelvis; however, Motani et al. (2014) argued that the flexible girdle is not a mandatory structure for viviparity, and that this factor may not be relevant for those species with many small embryos.

\subsection{Forelimb, pelvic girdle, hind limb and tail morphology of metriorhynchids: constraints on terrestrial displacement}

The metriorhynchid body plan contradicts the two general modes (crawling or walking) of reptilian terrestrial locomotion. Metriorhynchids had long hypocercal tails (approximately $50 \%$ of the total body length), supporting bilobed caudal flukes. In complete specimens of metriorhynchids, in which the height of the caudal fluke could be estimated (e.g., Cricosaurus suevicus, SMNS 9808; Rhacheosaurus gracilis, NHM R.3948), the length of the vertebral column that forms the tail bend is longer than the tibia/fibula (assuming a sprawling posture in which the limbs are held lateral to the body); or a few centimetres longer than femur + tibia/fibula (assuming an erect or semi-erect posture in which the limbs are held beneath the body). Also, in some specimens of Metriorhynchidae (e.g., Cricosaurus sp., MOZ-PV 066; Rhacheosaurus gracilis, NHM R.3948), some caudal vertebrae before the tail bend are apparently fused, giving more stiffness to this portion. Also, the paddle-like forelimbs of metriorhynchids are characterised by a short humerus (approximately $1 / 4$ of the femur length), a much reduced deltopectoral crest and rounded zeugopodial elements. It has been proposed that propulsion in metriorhynchids was achieved by lateral undulation of the tail (Massare 1988). On land, seal locomotion is achieved either by sinuous movement of the vertebral column, in which the limbs are not important, or by dragging the body with the forelimbs (Thewissen \& Taylor 2007). Land locomotion in metriorhynchids provided by lateral movements of the vertebral column, as seen in seals, seems unlikely. This kind of locomotion would have required that the last portion of the tail, probably a rigid structure (at least in some points), be dragged. The morphology of the forelimb in metriorhynchids indicates that it could not drag the body, or even support the body out of the water. Based on these features, we discard a crawling mode similar to seals and marine turtles. Marine turtles use simultaneous symmetrical movements of the forelimbs, and the hind limbs only provide some assistance (Thewissen \& Taylor 2007).
The pelvic girdle provides major attachment sites for muscles related to the movements of the hind limb; the reduced pelvic girdle of metriorhynchids, as well as the reduced areas for muscle attachments, suggests that the hind limb muscles were similarly reduced. In extant crocodiles, most of the muscles acting during the extension of knee and hip, as well as abduction and adduction (e.g., M. iliotibiales, M. iliofibularis, $M$. iliofemoralis, MM. flexor tibiales, amongst others), have their origin in the dorsolateral aspect of the ilium (see Carrano \& Hutchinson 2002; Otero et al. 2010, and references therein). The reduction of this region in the ilium of metriorhynchids suggests that these muscles were also reduced, implying that these kinds of movements were limited. Also, the reduction of the fourth trochanter in metriorhynchids indicates the reduction of M. caudofemoralis longus (Hua \& Buffetaut 1997). To this must be added the reduced and ventrally deflected transverse processes of the first caudal vertebrae, which would have restricted the expansion of the caudal hypaxial musculature (Herrera et al. 2013b). M. caudofemoralis longus and M. caudofemoralis brevis are mainly retractors of the femur (e.g., Gatesy 1990; Carrano \& Hutchinson 2002; Otero et al. 2010), and their inferred reduction indicates a limited capability of retraction of the femur. Notably, the posterior propodial pattern of metriorhynchids (femur compressed dorsoventrally, sigmoidal but without the typical torsion of the shaft, and with proximal and distal condyles in the same plane as the femoral shaft) strongly resembles those of the anterior propodials of other marine reptiles, in which this arrangement has been related to a change of the limb posture and the reduced need to support the body mass out of water (Chen et al. 2014). Also, the distal articular surfaces of the femur do not form differentiated condyles and are flattened and quadrangular, disposed on the same plane and forming a $45^{\circ}$ angle between them (Herrera et al. 2013b). This morphology seriously limits the possibility that this articulation could have acted as a functional knee.

Another aspect that needs to be considered is related to the bone microstructure of the femur. The microstructure of the metriorhynchid femur is consistent with the pattern observed in obligatory aquatic tetrapods. Thus, from the two main patterns observed in tetrapods with this lifestyle (i.e., increased or decreased bone density; see Houssaye 2013 for a review), the metriorhynchid femur is characterised by a decrease in bone density. This pattern hampered the body being supported out of the water without risk of bone damage. Notably, in the case of sea turtles which crawl for egg-laying, humeral microanatomy cannot be correlated with their lifestyle (Nakajima et al. 2014).

In conclusion, even though metriorhynchids were capable of standing up on land, the proportion of the limbs and the long hypocercal tails would have hampered both modes of locomotion. The present authors consider that this morphological evidence contradicts the possibility that metriorhynchids were capable of crawling or walking out of the water.

\subsection{Constraints on the evolution of viviparity}

Viviparity is a widespread reproductive strategy amongst vertebrates, and has evolved independently at least 150 times (115 times amongst squamate reptiles), indicating selective advantages of this reproductive strategy across a wide range of evolutionary histories and lifestyles (Andrews \& Mathies 2000; Shine 2005). Repeated evolution of viviparity across major vertebrate clades indicates that this reproductive mode can provide a strong selective advantage under some conditions. Although the particular conditions that favour the evolution of viviparity are not yet fully understood (Sites et al. 2011; 
Lambert \& Wiens 2013), the adaptation led to numerous radiations of secondarily-adapted marine amniotes (Motani et al. 2014), with its oldest occurrence in the Permian marine Mesosaurus (Piñeiro et al. 2012), and widespread amongst major Mesozoic marine clades such as ichthyopterigians, sauropterygians and mosasaurs (e.g., Caldwell \& Lee 2001; Renesto et al. 2003; Cheng et al. 2004; O'Keefe \& Chiappe 2011; Motani et al. 2014). Evolutionary transitions between oviparity and viviparity are not only frequent among reptiles, but also reversible (Lynch \& Wagner 2010; Pyron \& Burbrink 2014), reflecting evolutionary plasticity. Quite interesting also is the fact that the reproductive mode (i.e., oviparity $v s$. viviparity) is not taxonomically restricted. Thus, both distinct modes of reproduction co-occur amongst different species of the lizard Phrynocephalus (Jin \& Brown 2013), among populations of the same species in Salamandra salamandra (Buckley et al. 2007) and in the lizards Lerista bougainvillii (Qualls et al. 1995), Saiphos equalis (Smith \& Shine 1997) and Zootoca vivipara (Braña 1986).

Despite increasing interest in viviparity in recent years, constraints on its evolution in certain lineages remain elusive. It has never been documented in turtles or archosaurs. Rafferty et al. (2013) suggested that hypoxia in the oviduct arrests embryonic development and may constrain the evolution of viviparity in turtles; however, the underlying mechanisms that could reduce the diffusive capacity of the oviducts, and/or if it is exclusive to turtles, is still unclear. Blackburn \& Evans (1986), analysing morphological and/or physiological putative factors incompatible with viviparity in birds, concluded that no single avian feature is inherently incompatible with viviparous production of small clutches, and that the absence of the live-bearing mode is a consequence of the lack of selection for the intermediate evolutionary stage of egg retention. Recent research on viviparity and associated modes of fetal nutrition has produced some interesting results. Reproductive patterns in vertebrates, and the widespread occurrence of viviparity, are products of convergent evolutionary trends (Blackburn 2015), and some features that play a central role in embryonic development, such as the endocrine properties of extraembryonic membranes that have traditionally been viewed as a characteristic of placental amniotes, also characterise the chorioallantoic membrane of turtles, birds and crocodilians (Albergotti et al. 2009; Cruze et al. 2013).

3.3.1. Egg-laying. Hypoxia plays a central role in the development of amniote eggs in general. As gas diffusion is considerably slower in water than in air, amniote eggs are physiologically incapable of developing underwater, even in forms in which eggs are laid in seasonal ponds. Experimental studies on the northern snake-necked turtle, Chelodina rugosa, provide direct evidence that hypoxia maintains developmental arrest in this species. The rigid-shelled eggs are laid under water in seasonal ponds, and the embryos remain in developmental arrest as long as the eggs are immersed in water. Embryos resume development only after the soil dries and oxygen tension rises (Kennett et al. 1993). In experiments in which eggs were shifted from water to an atmosphere of pure nitrogen, embryos remained in developmental arrest; they resumed development only when exposed to atmospheric air (Andrews \& Mathies 2000).

\subsection{Testing the hypotheses}

3.4.1. Hypothesis 1. Like all archosaurs, metriorhynchids were oviparous. Taking this hypothesis into account, two derived hypotheses arise and therefore need to be tested: (a) metriorhynchids laid their eggs in the water; and (b) metriorhynchids laid their eggs out of water. Given that amniote eggs are physiologically incapable of developing underwater, derived hypothesis (a) is rejected. On the other hand, if metriorhynchids were oviparous, they must have been capable of locomotion on land for egg-laying. However, the metriorhynchid body plan contradicts the possibility of crawling or walking on land. Forelimbs shorter than the hind limbs and transformed into paddles indicate that body support on land (in both cases, crawling or walking) would have to rely on the hind limbs. However, limb morphology, reduced pelvic girdle and long hypocercal tails do not support these possibilities. Propulsion mechanisms out of the water, similar to those of marine turtles and/or seals, are discarded, mainly based on the morphology of the forelimb and the long hypocercal tail of metriorhynchids. Femur microstructure, characterised by bone lightening, provides an auxiliary argument against the possibility of effective body support outside the aquatic medium. For these reasons, derived hypothesis (b) is rejected.

3.4.2. Hypothesis 2. Metriorhynchids were viviparous. This hypothesis is contradicted by the phylogenetic position of metriorhynchids as archosaurs. A survey of the literature of vertebrate reproductive biology depicts the evolutionary plasticity of viviparity. It is widespread among major vertebrate lineages; it has evolved convergently in all major pelagic marine amniote lineages; it is putatively reversible (although infrequent); and it is not taxonomically restricted (both oviparity and viviparity co-occur in different populations of the same species in salamanders and lizards). It is notable that no factor or mechanism inhibiting viviparity in archosaurs has been confidently identified. On the other hand, recent findings indicate that endocrine activity of extraembryonic membranes, a feature traditionally considered as characteristic of placental amniotes, is a conserved trait of amniotes, and has been documented in turtles, birds and crocodilians. Taking into account that metriorhynchids were viviparous forms, the derived hypothesis is that metriorhynchid females could have enough space within the pelvic region to retain embryos and allow gas exchange between the oviduct and the embryonic membranes. The evidence that supports the derived hypothesis is the morphology of the pelvic region, which parallels that of the pelvic area of other live-bearing Mesozoic diapsids.

\section{Conclusions}

We tested two alternative hypotheses about reproductive strategies in metriorhynchids: the egg-laying (hypothesis 1) vs. the live-bearing (hypothesis 2). Given the lack of direct evidence supporting one or the other hypothesis, we proceeded from the most conservative hypothesis (hypothesis 1), searching not for theoretical and empirical cases that support them (inductive strategy) but searching for the empirical data or theoretical cases that refute them (counter-inductive strategy). Whilst several cases contradict hypothesis 1, we found no cases contradicting hypothesis 2 , except that metriorhynchids were archosaurs. What is interesting about this case is that the same data that refute hypothesis 1 support hypothesis 2, and vice-versa. Although considering viviparity as the reproductive strategy in metriorhynchids is unorthodox, the repetitive convergent evolution of viviparity amongst amniotes, and its reversibility (although infrequent), reflects the evolutionary plasticity of the oviparity to viviparity transition. For these reasons, hypothesis 1 is refuted.

\section{Acknowledgements}

We are especially grateful to N. Muñoz and A. Otero (MLP) for their technical support in the use of 3D scanner and related software, and to N. Toledo (MLP) for the construction ideas about musculature. We would like thank L. Acosta Burllaile 
(MLP) for preparation of the specimens. We also thank S. Vizcaíno, E. N. K. Clarkson and B. E. Schoenemann for the invitation to contribute to the present volume. D. Pol (MEF) and an anonymous reviewer provided helpful comments on earlier drafts of the manuscript. W. Joyce, P. Havrlik and M. Aiglstorfer (GPIT), R. Schoch (SMNS), L. Steel (NHM) and A. Garrido and B. Bollini (MOZ) are thanked for providing access to the collections in their care. This work was supported by: Agencia Nacional de Promoción Científica y Tecnológica (PICTs 2012-0748, 2013-0618, 2013-0663); Consejo Nacional de Investigaciones Científicas y Técnicas (PIP 0433); and Programa de Incentivos Universidad Nacional de La Plata N749 and N775 (Argentina). YH would like to thank the Alexander von Humboldt Foundation for a Humboldt Research Fellowship for Postdoctoral Researchers.

\section{References}

Albergotti, L. C., Hamlin, H. J., McCoy, M. W. \& Guillette, L. J. Jr. 2009. Endocrine activity of extraembryonic membranes extends beyond placental amniotes. PLOSONE 4, e5452. doi:10.1371/ journal.pone.0005452.

Andrews, C. W. 1913. A descriptive catalogue of the marine reptiles of the Oxford Clay. Part II. London: British Museum. 206 pp.

Andrews, R. M. \& Mathies, T. 2000. Natural history of reptilian development: Constraints on the evolution of viviparity. Bioscience 50, 227-38.

Blackburn, D. G. 1994. Discrepant usage of the term "ovoviviparity" in the herpetological literature. Herpetological Journal 4, 65-72.

Blackburn, D. G. 1999. Viviparity and oviparity: Evolution and reproductive strategies. Encyclopedia of Reproduction 4, 994-1003.

Blackburn, D. G. 2015. Evolution of vertebrate viviparity and specializations for fetal nutrition: a quantitative and qualitative analysis. Journal of Morphology 276, 961-90.

Blackburn, D. G. \& Evans, H. E. 1986. Why are there no Viviparous Birds? The American Naturalist 128, 165-90.

Braña, F. 1986. Ciclo reproductor y oviparismo de Lacerta vivipara en la Cordillera Cantábrica. Revista Española de Herpetología 1, 273-91.

Buckley, D., Alcobendas, M., García-París, M. \& Wake, M. H. 2007. Heterochrony, cannibalism and the evolution of viviparity in Salamandra salamandra. Evolution \& Development 9, 105-15.

Buffrénil, V., Bardet, N., Pereda-Suberbiola, X. \& Bouya, B. 2008. Specialization of bone structure in Pachyvaranuscrassispondylus Arambourg, 1952, an aquatic squamate from the Late Cretaceous of the southern Tethyan margin. Lethaia 41, 59-69.

Caldwell, M. W. \& Lee, M. S. Y. 2001 Live bearing in Cretaceous marine lizards: first fossil record of viviparity in squamates. Proceedings of the Royal Society, London, Series B 268, 2397-2401.

Carrano, M. T. \& Hutchinson, J. R. 2002. Pelvic and hind limb musculature of Tyrannosaurus rex (Dinosauria: Theropoda). Journal of Morphology 253, 207-28.

Chen, X-h., Motani, R., Cheng, L., Jiang, D-y. \& Rieppel, O. 2014. The enigmatic marine reptile Nanchangosaurus from the Lower Triassic of Hubei, China and the phylogenetic affinities of Hupehsuchia. PLoSONE 9, e102361. doi:10.1371/journal.pone.0102361.

Cheng, Y. N., Wu, X. C. \& Ji, Q. 2004. Triassic marine reptiles gave birth to live young. Nature 432, 383-86.

Chinsamy-Turan, A. 2005. The Microstructure of Dinosaur Bone: Deciphering Biology With Fine-Scale Techniques. Baltimore: Johns Hopkins University Press. 216 pp.

Claessens, L. P. A. M. \& Vickaryous, M. K. 2012. The evolution, development and skeletal identity of the crocodylian pelvis: Revisiting a forgotten scientific debate. Journal of Morphology 273, 1185-98.

Cruze, L., Hamlin, H. J., Kohno, S., McCoy, M. W. \& Guillette Jr., L. J. 2013. Evidence of steroid hormone activity in the chorioallantoic membrane of a Turtle (Pseudemysnelsoni). General and Comparative Endocrinology 186, 50-57.

Fernández, M. \& Gasparini, Z. 2000. Salt glands in a Tithonian metriorhynchid crocodyliform and their physiological significance. Lethaia 33, 269-76.

Fernández, M. \& Gasparini, Z. 2008. Salt glands in the Jurassic metriorhynchid Geosaurus: implications for the evolution of osmoregulation in Mesozoic marine crocodyliforms. Naturwissenschaften 95, 79-84.
Fraas, E. 1902. Die Meer-Crocodilier (Thalattosuchia) des oberen Jura unter specieller Berücksichtigung von Dacosaurus und Geosaurus. Palaeontographica 49, 1-79.

Gasparini, Z. 1978. Consideraciones sobre los Metriorhynchidae (Crocodilia, Mesosuchia): su origen, taxonomía y distribución geográfica. Obra del Centenario del Museo de La Plata 5, 1-9.

Gasparini, Z. 1981. Los Crocodylia fósiles de la Argentina. Ameghiniana 18, 177-205.

Gasparini, Z. B. de, \& Dellapé, D. 1976. Un nuevo cocodrilo marino (Thalattosuchia, Metriorhynchidae) de la Formación Vaca Muerta (Tithoniano) de la Provincia de Neuquén (Argentina). Actas $1^{\circ}$ Congreso Geológico Chileno, Santiago, Chile, C1-C21.

Gatesy, S. M. 1990. Caudofemoral musculature and the evolution of theropod locomotion. Paleobiology 16, 170-86.

Herrera, Y., Fernández, M. S. \& Gasparini, Z. 2013a. The snout of Cricosaurus araucanensis: a case study in novel anatomy of the nasal region of metriorhynchids. Lethaia 46, 331-40.

Herrera, Y., Fernández, M. S. \& Gasparini, Z. 2013b. Postcranial skeleton of Cricosaurus araucanensis (Crocodyliformes: Thalattosuchia): morphology and palaeobiological insights. Alcheringa: An Australasian Journal of Palaeontology 37, 285-98.

Houssaye, A. 2013. Bone histology of aquatic reptiles: what does it tell us about secondary adaptation to an aquatic life? Biological Journal of the Linnean Society 108, 3-21.

Hua, S. \& de Buffrénil, V. 1996. Bone histology as a clue in the interpretation of functional adaptations in the Thalattosuchia (Reptilia, Crocodylia). Journal of Vertebrate Paleontology 16, 703-17.

Hua, S. \& Buffetaut, E. 1997. Crocodilia. In Callaway, J. \& Nicholls, E. (eds) Ancient Marine Reptiles, 357-74. California: San Diego Academic Press. 502 pp.

Jin, Y. T. \& Brown, R. P. 2013. Species history and divergence times of viviparous and oviparous Chinese toad-headed sand lizards (Phrynocephalus) on the Qinghai-Tibetan Plateau. Molecular Phylogenetics and Evolution 68, 259-68.

Kennett, R., Georges, A. \& Palmer-Allen, M. 1993. Early developmental arrest during immersion of eggs of a tropical freshwater turtle, Chelodina rugosa (Testudinata: Chelidae), from Northern Australia. Australian Journal of Zoology 41, 37-45.

Lambert, S. M. \& Wiens, J. J. 2013. Evolution of viviparity: a phylogenetic test of the cold-climate hypothesis in phrynosomatid lizards. Evolution 67, 2614-30.

Lee, A. H. 2004. Histological organization and its relationship to function in the femur of Alligator mississippiensis. Journal of Anatomy 204, 197-207.

Lynch, V. J. \& Wagner, G. P. 2010. Did egg-laying boas break Dollo's law? Phylogenetic evidence for reversal to oviparity in sand boas (Erix: Boidae). Evolution 64, 207-16.

Martin, J. E. \& Vincent, P. 2013. New remains of Machimosaurushugii von Meyer, 1837 (Crocodilia, Thalattosuchia) from the Kimmeridgian of Germany. Fossil Record 16, 179-96.

Massare, J. A. 1988. Swimming capabilities of mesozoic marine reptiles: implications for method of predation. Paleobiology 14, 187-205.

Motani, R., Jiang, D-y., Tintori, A., Rieppel, O. \& Chen, G-b. 2014. Terrestrial origin of viviparity in Mesozoic marine reptiles indicated by Early Triassic embryonic fossils. PLOSONE 9, e88640. doi:10.1371/journal.pone.0088640.

Mueller-Töwe, I. J. 2006. Anatomy, phylogeny, and palaeoecology of the basal thalattosuchians (Mesoeucrocodylia) from the Liassic of Central Europe. Unpublished PhD Thesis, Universität Mainz, Germany.

Nakajima, Y., Hirayama, R. \& Endo, H. 2014. Turtle humeral microanatomy and its relationship to lifestyle. Biological Journal of the Linnean Society 112, 719-34.

Neill, W. T. 1971. The last of the ruling reptiles: Alligators, Crocodiles and their kin. New York \& London: Columbia University Press. $486 \mathrm{pp}$.

O'Keefe, F. R. \& Chiappe, L. M. 2011. Viviparity and K-Selected life history in a Mesozoic marine plesiosaur (Reptilia, Sauropterygia). Science 333, 870-73.

Organ, C. L., Janes, D. E., Meade, A. \& Pagel, M. 2009. Genotypic sex determination enabled adaptive radiations of extinct marine reptiles. Nature 461, 389-92.

Otero, A., Gallina, P. A. \& Herrera, Y. 2010. Pelvic musculature and function of Caiman latirostris. Herpetological Journal 20, 173-84.

Pierce, S. E. \& Benton, M. J. 2006. Pelagosaurus typus Bronn, 1841 (Mesoeucrocodylia: Thalattosuchia) from the Upper Lias (Toarcian, Lower Jurassic) of Somerset, England. Journal of Vertebrate Paleontology 26, 621-35.

Piñeiro, G., Ferigolo, J., Meneghel, M. \& Laurin, M. 2012. The oldest known amniotic embryos suggest viviparity in mesosaurs. Historical Biology 24, 620-30. 
Pyron, R. A. \& Burbrink, F. T. 2014. Early origin of viviparity and multiple reversions to oviparity in squamate reptiles. Ecology letters 17, 13-21.

Qualls, C., Shine, R., Donnellan, S. \& Hutchinson, M. 1995. The evolution of viviparity within the Australian scincid lizard Lerista bougainvillii. Journal of Zoology 237, 13-26.

Rafferty, A. R., Evans, R. G., Scheelings, T. F. \& Reina, R. D. 2013. Limited oxygen availability in utero may constrain the evolution of live birth in reptiles. American Naturalist 181, 245-53.

Renesto, S., Lombardo, C., Tintori, A. \& Danini, G. 2003. Nothosaurid embryos from the Middle Triassic of northern Italy: an insight into the viviparity of nothosaurs? Journal of Vertebrate Paleontology 23, 957-60.

Shine, R. 2005. Life-history evolution in reptiles. Annual Review of Ecology, Evolution, and Systematics 36, 23-46.

Sites Jr, J. W., Reeder, T. W. \& Wiens, J. J. 2011. Phylogenetic insights on evolutionary novelties in lizards and snakes: sex, birth, bodies, niches, and venom. Annual Review of Ecology, Evolution, and Systematics 42, 227-44.
Smith, S. A. \& Shine, R. 1997. Intraspecific variation in reproductive mode within the scincid lizard Saiphos equalis. Australian Journal of Zoology 45, 435-45.

Thewissen, J. G. M. \& Taylor, M. A. 2007. Aquatic adaptations in the limbs of amniotes. In Hall, B. K. (ed.) Fins into Limbs: Evolution, Development, and Transformation, 310-322. Chicago: University of Chicago Press. 344 pp.

Wilkinson, L. E., Young, M. T. \& Benton, M. J. 2008. A new metriorhynchid crocodile (Mesoeucrocodylia: Thalattosuchia) from the Kimmeridgian (Upper Jurassic) of Wiltshire, UK. Palaeontology 51, 1307-33.

Young, M. T., Brusatte, S. L., Ruta, M. \& Andrade, M. B. 2010. The evolution of Metriorhynchidea (Mesoeucrocodylia, Thalattosuchia): an integrated approach using geometric morphometrics, analysis of disparity and biomechanics. Zoological Journal of the Linnean Society 158, 801-59.

Young, M. T., Andrade, M. B., Brusatte, S. L., Sakamoto, M. \& Liston, J. 2013. The oldest known metriorhynchid super-predator: a new genus and species from the Middle Jurassic of England, with implications for serration and mandibular evolution in predacious clades. Journal of Systematic Palaeontology 11, 475-513. 
